\title{
Enhanced AFCl Sampling, Analysis, and Safeguards Technology Review
}

Del Bowers

Roger Henry

Jack Law

Steve Lamont

Dave Meikrantz

John Svoboda

September 2009

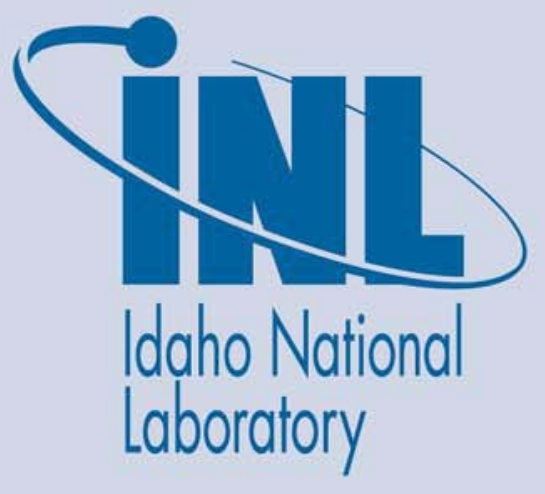

The INL is a U.S. Department of Energy National Laboratory operated by Battelle Energy Alliance 


\title{
Enhanced AFCI Sampling, Analysis, and Safeguards Technology Review
}

\author{
Del Bowers ${ }^{1}$ \\ Roger Henry \\ Jack Law \\ Steve Lamont ${ }^{2}$ \\ Dave Meikrantz \\ John Svoboda \\ ${ }^{1} \mathrm{ANL}$ \\ September 2009 \\ Idaho National Laboratory \\ Idaho Falls, Idaho 83415 \\ http://www.inl.gov \\ Prepared for the \\ U.S. Department of Energy \\ Office of Nuclear Energy \\ Under DOE Idaho Operations Office \\ Contract DE-AC07-05ID14517
}




\section{DISCLAIMER}

This information was prepared as an account of work sponsored by an agency of the U.S. Government. Neither the U.S. Government nor any agency thereof, nor any of their employees, makes any warranty, expressed or implied, or assumes any legal liability or responsibility for the accuracy, completeness, or usefulness, of any information, apparatus, product, or process disclosed, or represents that its use would not infringe privately owned rights. References herein to any specific commercial product, process, or service by trade name, trade mark, manufacturer, or otherwise, does not necessarily constitute or imply its endorsement, recommendation, or favoring by the U.S. Government or any agency thereof. The views and opinions of authors expressed herein do not necessarily state or reflect those of the U.S. Government or any agency thereof. 



\section{SUMMARY}

The focus of this study includes the investigation of sampling technologies used in industry and their potential application to nuclear fuel processing. The goal is to identify innovative sampling methods using state-of-the-art techniques that could evolve into the next-generation sampling and analysis system for metallic elements.

Sampling and analysis of nuclear fuel recycling plant processes is required both to monitor the operations and ensure Safeguards and Security goals are met. In addition, environmental regulations lead to additional samples and analysis to meet licensing requirements. The volume of samples taken by conventional means, can restrain productivity while results samples are analyzed, require process holding tanks that are sized to meet analytical issues rather than process issues (and that create a larger facility footprint), or, in some cases, simply overwhelm analytical laboratory capabilities. These issues only grow when process flowsheets propose new separations systems and new byproduct material for transmutation purposes. Novel means of streamlining both sampling and analysis are being evaluated to increase the efficiency while meeting all requirements for information.

This report addresses just a part of the effort to develop and study novel methods by focusing on the sampling and analysis of aqueous samples for metallic elements. It presents an overview of the sampling requirements, including frequency, sensitivity, accuracy, and programmatic drivers, to demonstrate the magnitude of the task. The sampling and analysis system needed for metallic element measurements is then discussed, and novel options being applied to other industrial analytical needs are presented. Inductively-coupled mass spectrometry instruments are the most versatile for metallic element analyses and are thus chosen as the focus for the study. Candidate novel means of process sampling, as well as modifications that are necessary to couple such instruments to introduce these samples, are discussed.

A suggested path forward based on an automated microchip capillary-based sampling system interfaced to the analysis spectrometer is presented. The ability to obtain micro-liter volume samples coupled with remote automated means of sample tracking and transport to the instrument would greatly improve analytical efficiency while reducing both personnel exposure and radioactive waste. Application of this sampling technique to new types of mass spectrometers for selective elemental isotopic analysis could also provide significant improvements in safeguards and security analyses. 


\section{ACKNOWLEDGEMENTS}

The authors would like to acknowledge the contributions of Emmett Soffey and Kenichic Sakata, Agilent Technologies' ICP-MS Product Specialists for their help with identifying the input and output streams of the inductively-coupled mass spectrometer as defined in Appendix A. 


\section{CONTENTS}

SUMMARY iii

ACKNOWLEDGEMENTS . V

ACRONYMS ix

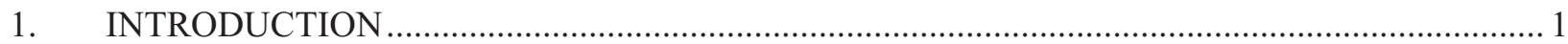

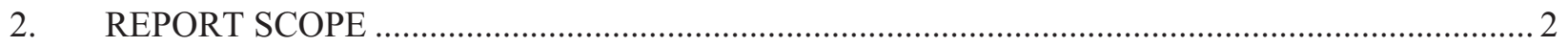

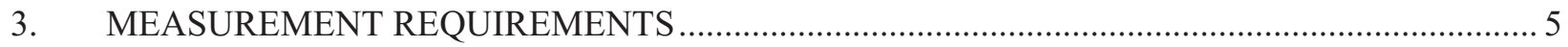

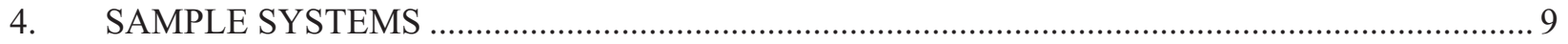

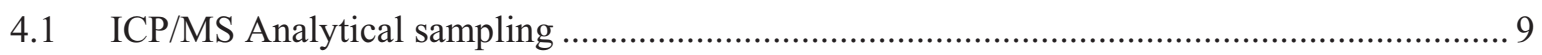

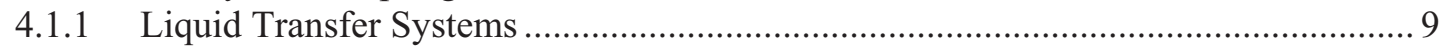

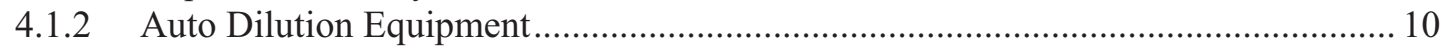

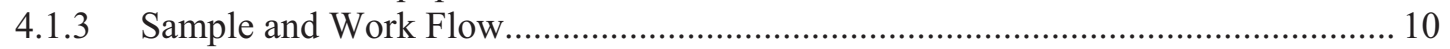

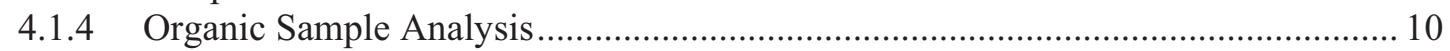

4.2 Analytical Instrument Systems Recommended for Application Test/Development

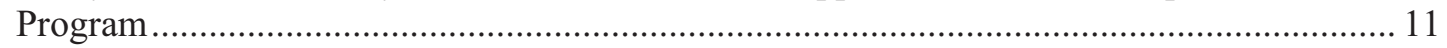

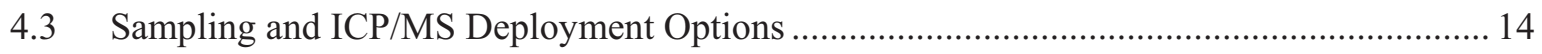

4.4 Sample Systems Recommended for Application Test Development Program ..................... 14

4.5 Micro Nebulizer Coupled to a Micro ICP Generator - The Future ..................................... 17

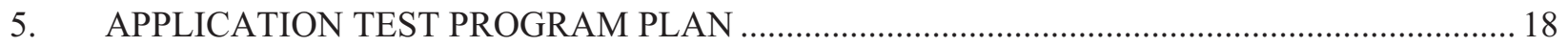

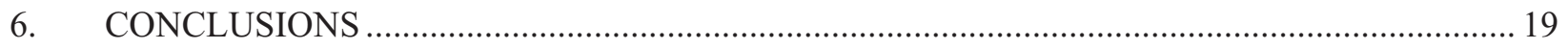

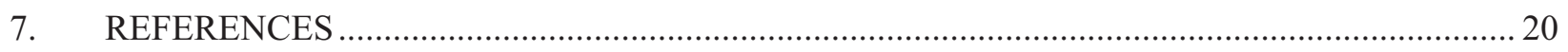

Appendix A-Inductively-Coupled-Plasma Mass Spectrometer: A Definition, Including Input and Output Streams

\section{FIGURES}

Figure 1. Overview of sampling requirements.

Figure 2. Detection limits for ${ }^{239} \mathrm{Pu}$ in uranium solutions. The use of a dynamic-reaction cell with an ICP-QMS actually produced better detection limits that using a SF-ICP/MS for the same analyses. ${ }^{1}$

Figure 3. Measurement precision for Total $U$ (left plot) and ${ }^{235} \mathrm{U} /{ }^{238} \mathrm{U}$ (right plot) for a range of sample uranium contents. Note the log scale for the Total U axis. Given sufficient uranium, there is no benefit to using the lower resolution modes available with SF-ICP/MS. The precision converges to an approximate best value of $0.5 \%$ relative standard deviation $(k=1)$ for total uranium and $0.7 \%$ relative standard deviation $(k=1)$ for the ${ }^{235} \mathrm{U} /{ }^{238} \mathrm{U}$ ratio. 
Figure 4. Estimated limits of detection for select isotopes in a $50 \mathrm{mg} / \mathrm{L}$ uranium solution. Note that the SF-ICP/MS allows resolution to be varied. At higher resolutions, it is easier to discriminate against interfering polyatomic ions while, at lower resolutions, overall sensitivity is usually better. ${ }^{2}$ 13

\section{TABLES}

Table 1. Typical capabilities for three common ICP/MS instruments................................................. 13 


\section{ACRONYMS}

AFCI Advanced Fuel-Cycle Initiative

ANL Argonne National Laboratory

COEX Co-extraction of actinides

ES\&H Environmental, Safety, and Health

HR-ICP/MS High-resolution inductively-coupled/mass spectrometer

IAEA International Atomic Energy Agency

$\mathrm{ICP} / \mathrm{MS} \quad$ Inductively-coupled mass spectrometer

ICP-QMS Inductively-coupled quadrupole mass spectrometer

INL Idaho National Laboratory

LANL Los Alamos National Laboratory

Ld Detection limit

MC\&A Material Control and Accountability

MC-ICP/MS Multi-collector inductively-coupled/mass spectrometer

NNSA National Nuclear Security Agency

PUREX Plutonium-uranium extraction

R\&D Research and development

RF Radio frequency

SFTF Spent Fuel Treatment Facility

SNM Special nuclear material

TARIS Thermal atomization resonance ionization spectroscopy

TBP Tributyl phosphate

TIMS Thermal-ionization mass spectrometry

TRUEX Transuranic extraction.

UREX Uranium extraction (includes technetium). 


\section{ENHANCED AFCI SAMPLING, ANALYSIS, AND SAFEGUARDS TECHNOLOGY REVIEW}

\section{INTRODUCTION}

This report is intended to identify major challenges for defining and testing improvements to current sampling and analytical techniques and the benefits that can be gained when these concepts are implemented in future reprocessing facility designs. The goal is to create transcendental improvements in all areas: reduced proliferation risks, improved operational control and efficiency, reduced analytical waste, reduced facility footprint (analytical and process areas) and capital costs, decreased personnel exposure, etc. The following subsections discuss the general components and design requirements of a research and development (R\&D) program that can develop the next generation of advanced sampling and analysis technologies for processing used nuclear fuel and other nuclear materials via both "wet" (aqueous) and "dry" (electrochemical) techniques. This discussion provides a comprehensive view of the work scope for aqueous sampling. These tasks will be completed in phases, focusing first on aqueous sampling and analysis to provide an integrated set of accomplishments that may complement all challenges. Thus, a similar set of issues may be identified for the dry electrochemical process, but they will be addressed in a future work scope that may benefit from these first efforts.

The initial phase of the overall program is focused on the collection of information related to aqueous sampling techniques to support process control, Material Control and Accountability (MC\&A), and Environmental, Safety, and Health (ES\&H). The current aqueous sampling and analytical techniques are based on process methods, designed in the 1970s, which included significant step improvements in some areas over the 1950 s designs.

The initial objectives of this study include the investigation of sampling technologies used throughout the industry, their potential application to fuel reprocessing, and the identification of innovative methods using of state-of-the-art techniques that may evolve into applicable sampling systems. These selected concepts and systems will be screened so superior candidates can be tested and evaluated for use in future facility designs to maximize "Safeguards by Design" features and provide significant process enhancements for optimal performance and protection against proliferation of nuclear materials. The development of these concepts and systems will need to be proven at the research level before consideration at the engineering or commercial scale. Once proven, the future engineering-scale pilot testing facility will demonstrate advanced MC\&A measures for all of the testing programs. In addition, it will test the performance of next-generation sampling and analytical concepts to further advance capabilities in the areas of accuracy, near-real-time accountability, reliability, etc. The advanced safeguards requirements thus developed will satisfy both national and international monitoring requirements.

The following subsections provide an overview of the aqueous sampling program that is typical of today's reprocessing plants and then focus the discussion to the specifics of defining in what areas and ways improved sampling and analytical techniques must be developed. Following that, recommendations of novel sampling methods currently being used in industry that may be applied to nuclear recycling are offered, along with the required sample-transport and analytical interfaces that need to be developed. 


\section{REPORT SCOPE}

The following paragraphs describe the aqueous sampling systems issues that are typical for current processing facilities and the overall challenge to derive significant gains from improved sampling and analytical techniques. Section 3.0 discusses the sampling needs and sampling points using a candidate uranium extraction (UREX) process flow sheet that is applicable for analysis with an ICP/MS. This discussion of the big picture is then focused, in Section 4.0, on the primary subject of this study by taking a much closer look at one of the critical path issues: that is, strategies for improving inductively-coupled plasma/mass spectrometer (ICP/MS) analysis and its sampling system. Section 5.0 defines high level research and development requirements for follow on test programs. Appendix A discusses the ICP/MS in terms of its input, output, sample requirements and the resultant waste streams. This analysis leads us to believe that even microliter size samples if efficiently introduce into the ICP/MS could provide adequate ion for accurate sample analyis with minimal waste generation.

Within the separations processes, the potential value-added results from advanced sampling and analytical methods cannot be ignored. These advances are expected to provide timely analytical results that can minimize facility footprint (process area devoted to storage/surge capacity for analytical turnaround time and analytical laboratory space), ensure timely process control, safeguards, operational safety, minimized radiation exposure for analytical personnel, and significant reduction in analytical waste generation.

To cost-effectively design, build, and operate the next generation of fuel reprocessing facilities, multiple technological challenges require resolution before an optimal facility design and operation scheme can be defined. Facility footprint and timely analytical results are of primary importance and this importance increases with the number of separation systems and separated byproducts that result from flowsheet selection. Research and development that uses a combination of advanced instrumentation, control, and process modeling will eventually be employed to address these concerns:

- A complete understanding of the time/motion characteristics of each sample and its priority (process control, safeguards, safety)

- Identification of techniques that automate sampling and significantly simplify analysis in order to reduce turnaround time

- Identification of on-line monitoring and/or shielded in-line/tank analysis that reduce sampling, waste generation and turnaround time

- Integration of automated sample collection with on-line analysis to provide near-real-time analytical data.

- Optimization of sample size to reduce sample waste as well as reduce the time required for the analysis, thereby reducing surge capacity between the major process systems.

As previously mentioned, this report focuses on strategies for improving ICP/MS analysis and the associated automated-sampling systems. Other important related issues and topics are briefly discussed in the following bullet points to bound the scope of this report while predicting the potential for return on investment. Some of these topics will be addressed in the future to help provide an integrated sampling R\&D program:

- The investigation does not directly address sampling in pyroprocessing, but any sampling methods identified under this study that show potential for pyroprocessing sampling technologies will be listed.

- The investigation does not assume a separation between analysis technology and sample requirements. The ICP/MS is assumed to be the analysis instrument of choice, and it is thought that it can meet most aqueous analysis requirements. The problem, then, is to develop innovative ways to 
improve the collection of samples, the delivery of samples to the instrument, the analysis process (sample preparation, dilution, injection, cleaning, etc.), and waste management.

- The investigation is primarily constrained to liquid samples because they constitute the majority of the measurements that may be collected from any of the reprocessing paths that are under consideration for example, co-extraction of actinides (COEX), UREX, etc. Sampling of gasses and solids will be considered at a later time.

- The investigation does not directly address on-line non-destructive sampling technologies because this work is covered by Advanced Fuel-Cycle Initiative (AFCI) Safeguards and National Nuclear Security Agency (NNSA)-funded research. However, identification of areas in which these applications may show promise will be noted.

- The investigation identifies process control and criticality, safeguards, and environmental samples and samples collected for technical research data/information to help resolve optimization issues.

The goals of this initial investigation include identifying candidate concepts that can be tested to achieve the following:

- Minimize sample turnaround time from sample extraction and delivery to the analysis instrument to return of analytical data to the intended customer.

- Assure a representative sample at the minimum sample size.

- Minimize waste generation (in the form of sample bottles, analytical lab supplies, decontamination solutions and rinses, sample dilutions, etc.).

- Provide a user-friendly sampling-by-design process that results in, for example, minimal sample points, in-line or in-tank, sampling remote analysis to reduce collection and transport, collocation of remote-operated labs within sample stations, etc.

- Minimize worker time required to perform sampling by using automated, as opposed to manual, methods.

- Minimize radiological and chemical exposure of personnel during operation and maintenance.

- Minimize any potential for sample state change during transport, analysis and/or storage (by evaporation, decay, or chemical transitions, etc.) In those instances in which change of state cannot be avoided, characterize/understand the effects of the sample change on resulting measurements.

- Minimize calibration intervals and associated time and workforce requirements.

- Maximize the reliability and on-time availability of sampling equipment.

- Minimize time spent on data management, approvals and record keeping issues. This may be outside our scope unless we put more focus on the turn-around time issues.

- Minimize the uncertainty associated with new liquid-sample handling and preparation technology.

In addition to these generic sampling goals, the following Safeguards concepts need to be considered and integrated into the R\&D effort:

- Address International Atomic Energy Agency (IAEA) authentication issues so the IAEA can be confident that samples are taken from the stated location and represent the contents of the sampled solution. Examples include:

- Time stamps authenticating the extraction time and the arrival time at the analytic instrument

- Authentication of the location from which the sample was taken

- Authentication of proper homogenization prior to sampling. 
- Minimize sample transportation distances, the number of required samples, and the chain of custody.

- Automate, to the extent possible, sampling activities, considering:

- In-line (meaning both sensors and analysis equipment are located in the process-flow stream) or on-line (in which the sensors are located in the process-flow stream, but analysis equipment is located outside the stream). These two methods are preferred over human involvement in the measurement.

- Sampling equipment and equipment enclosures incorporate tamper-indicating technology and can be sealed to IAEA standards.

- Time spent on data management, approvals, record keeping and transparency/oversight issues is minimized.

- Measurements by operations personnel are performed applying a two-person rule, including an operator and an IAEA representative. Because this is a labor-intensive and, therefore, expensive way of operating, a better approach will be sought for those circumstances in which a process cannot be fully automated. 


\section{MEASUREMENT REQUIREMENTS}

The purpose of this section is to:

- Provide an overview or the basic sampling needs for an aqueous-separations work process. For the purpose of discussion, a candidate UREX flowsheet is used in order to grasp the complexity and scope of sampling and analytical support needed to provide timely analysis for process control, environmental/safety monitoring, MC\&A and process optimization and improvement.

- Identify the aqueous sample points needed for process control, including location, analysis, approximate accuracy, turnaround time, and ascertain the samples best supported by ICP/MS analysis.

An overview of sampling related findings from a recent multi-lab Spent Fuel Treatment Facility (SFTF) design scoping study is summarized below:

- Current in-process nuclear-materials determinations for process control and MC\&A monitoring typically require processing hold points, referred to as "feed" or "hold" tanks. These serve two principal purposes: they provide a location for the sampling draw and time for wet-chemistry analysis to be completed. They also decouple processing functions to help maintain smooth integrated operations. Whenever turnaround time for sampling and analysis exceeds the holding time required to maintain normal processing conditions, then sampling and analysis slows reprocessing and requires larger surge capacity between process steps. Capital costs increase (because larger facilities and larger vessels are needed), and operating cost increase due to unnecessary down time.

- Obtaining aqueous samples requires operating personnel to obtain and transfer the sample to an analytical laboratory. Wet-chemistry analysis typically results in radiation exposure to laboratory personnel and delays processing while analytical data is developed and verified. Radiological risk increases with the number of transfers and the amount (source term) of remote-handled radioactive material in the sample, as does waste generation from dilution of samples.

- Future U.S. plant designs will build on past lessons learned and are focused on providing timely, integrated analytical support to ensure process control and MC\&A as well as optimized facility sizing and operations.

- Manually supported wet chemistry labs are more expensive and slower than automated analytical systems.

- Multiple contact analytical techniques require dilutions, duplicate samples and increased turnaround time, waste generation, personnel exposure risk and cost.

- Sampling and analysis is complicated. Current techniques are complex for differentiating measurement of radionuclides with the same mass (for example, U-238 and $\mathrm{Pu}-238$ ).

- Process samples that are not diluted typically require remote-handling capabilities.

- Fissile material requires near-real-time tracking to detect diversion detection and to prevent an uncontrolled criticality resulting from the accumulation of critical masses in vessels/equipment/pipes/sumps that are not criticality safe.

- The time inertia of the current sampling and analytical processes is so high that it limits the frequency of sampling. Sampling frequency can also be limited by waste-generation concerns as well as cost and analytical turnaround time.

- A new world standard for MC\&A, as applied to spent-fuel processing, is desired to further enhance international acceptance of nuclear energy. 
Figure 1 depicts the separations process, starting with the receipt and storage of the used nuclear fuel and ending with the separated by-products and waste streams solidified and packaged for interim storage and/or off-site shipment. This spreadsheet is a work in progress and is intended to support this study and others that may follow so that the collective effort is integrated and available as one reference. The current evolution provides a detailed block-flow diagram of the process and cross references pre-conceptual vessel and line numbers to identify sampling and monitoring points. Three color codes are used to identify the basic purpose for collecting each sample. MC\&A-driven samples are shaded rose, Process-control or ES\&H samples are in green, and samples related to process-optimization are in blue. Figure 1 is also formatted so as to eventually provide an overview of the total number of sample points, the anticipated sample frequency, and the total number of samples that would be collected on an annual basis. This number can vary depending upon the complexity of the process but, historically, it has been in the range of several hundreds of thousands per year, which once again underscores the magnitude of the scope of analytical radiochemistry and the challenge to simplify and improve this vital support area. Other data columns are intended to gather information related to analytical accuracy, waste generation, turnaround time, and the like. Those liquid samples that are best suited for ICP/MS analysis are identified by an "X" in the box of the tan-colored column. 


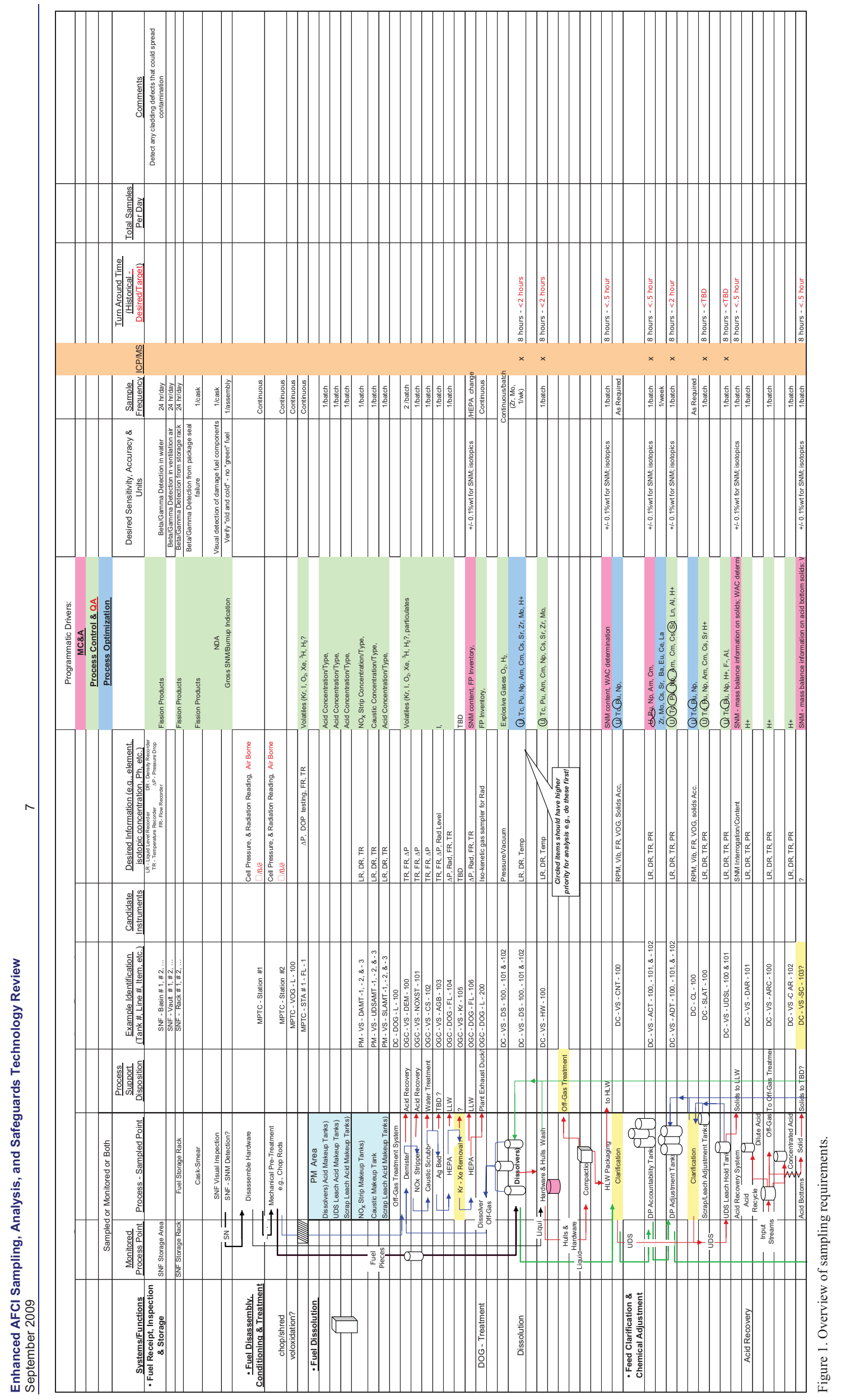




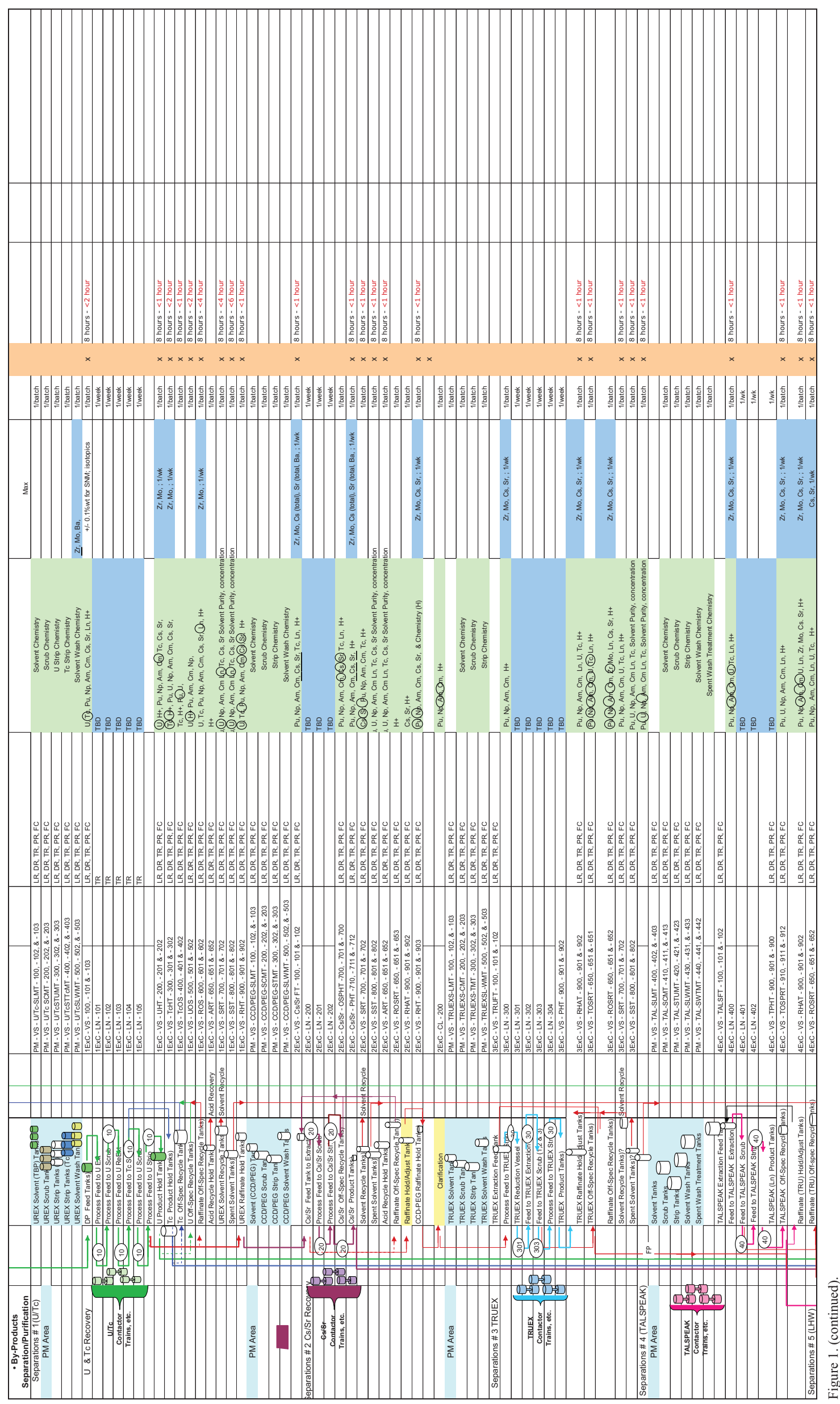




\section{SAMPLE SYSTEMS}

\subsection{ICP/MS Analytical sampling}

New sampling techniques will require development in support of advanced fuel-reprocessing technologies. These techniques will take advantage of new analytical techniques, improvements in the sensitivity of currently available techniques, and the revolution in data management, robotics, and electronics. Advanced designs will enable the integration of analysis with process, thus reducing response times and waste while improving safety and safeguards.

Traditionally, Hanford-type samplers were used to sample the various process streams in PUREX plants. While these air-lift samplers were effective, there was a significant cost in man-hours to perform the operations needed to obtain liquid samples. Air-lift samplers operate by recirculating the sample solution via two needles inserted into the septum of a sample bottle for a period of time sufficient to reach equilibrium. They were cumbersome to use and occasionally leaked at the septum interface. These samplers also have a large footprint compared to the sample size.

It is assumed that the next generation of reprocessing plants will use centrifugal contactors instead of the pulse columns used in current and earlier facilities. While this will reduce the footprint of the facility, there will still be a need to acquire samples at long distances from the central sampling hot cell.

Due to advances in analytical instrumentation, a much smaller sample of material is needed to accurately measure constituents of any process stream. Ideally, smaller samples can be collected so long as they are representative of the process streams from which they are taken. This is attractive in that there will be less waste generated from analyses, smaller quantities of material to be handled routinely, and a reduced amount of sample material either discarded or archived.

Smaller volumes create concerns about the accurate representation of the process: are the samples representative, and will the analytical system be reliable?

There are several options to perform ICP/MS analysis with smaller sample volumes using current technologies, including liquid transfer systems and auto dilution equipment.

\subsubsection{Liquid Transfer Systems}

Ideally one would like to use small-bore tubing to minimize the amount of liquid at the sample station. This will reduce the radioactive material inventory diverted from the process stream to the sampling cell. This reduction in fissile inventory will simplify the Safeguards and Security aspect of the analysis. To obtain a small-volume sample, narrow-diameter tubing could be used. To obtain a representative $1 \mathrm{~mL}$ sample from a $1000 \mathrm{~L}$ tank, one could locate a sample collection station on a continuous-flow loop along the process stream; collecting samples in-line directly from the flow. A continuous flow loop is preferable to a stop-flow-as-needed sampling system. By keeping a continuous flow, phase separation or settling will be minimized.

However, using smaller-diameter transfer tubing presents a challenge to ensuring a representative sample. Small diameter tubing will have a relatively lower flow rate if the tubing is long. Also, the small-bore tubing is more likely to develop blockages and plugging.

If there is only one analytical sampling hot cell, there will still be long runs of tubing to allow real-time analysis of multiple process streams. A hybrid system could provide both a representative sample and a small final sample volume in the hot cell. A hybrid system would use large tubing, as in the past, but tap into a system with a small-bore tube just prior to arrival at the sampling hot cell, which would allow return of the remaining sample volume to the source. This would prevent significant amounts of material from being added to the sampling cell inventory. This configuration requires only short runs of small-bore tubing, which will minimize tube plugging problems. The system will still require access for personnel to perform necessary remote repairs or replacement of small-bore tubing in the system via master/slave 
manipulators. A number of pumps can perform these transfers, including peristaltic, piston, and pneumatic pumps, thus reducing the need for air-lifts.

\subsubsection{Auto Dilution Equipment}

Using devices originally developed for the pharmaceutical industry could aid future analytical efforts at reprocessing plants. Diluters, for example, have become very sophisticated. Microlab systems, produced by Hamilton Corp, have the ability to pipette down to 1 microliter with an accuracy of $+/-1 \%$ and to dilute this sample to a volume of $1 \mathrm{~mL}$ in a single step. This tool looks promising for remote handling because it removes the need for individually manipulated pipettes for sampling and dilution. Use of these auto-diluters would greatly speed up the sampling and diluting steps necessary for many of the samples prior to introduction to analytical instrumentation.

\subsubsection{Sample and Work Flow}

Also routinely used by the pharmaceutical industry, bar-coded vials are used with sample-storage boxes indexed for rapid retrieval using robotics. Companies such as Cargille, Thermo Scientific, Xiril, Zymark, and Alegro Technologies supply equipment for different major R\&D efforts that require the handling of large numbers of samples. Bar-coded samples would be placed into the boxes and retrieved by robotic equipment. These samples could be archives or active analytical samples queued for analysis. Robotic arms could pick up individual samples and move them to the auto-dilution station or ICP/MS instrument auto sampler.

Laboratory information management systems (LIMS) have been in use for decades. LIMS software, used in the laboratory, automates the management of samples, instruments, standards, work flow and quality control, and it makes a record of laboratory users. For example, a LIMS can be used to direct a robotics system to dilute or prepare samples for analysis. Process knowledge is used to set up the LIMS methods. Appropriate dilutions would then automatically be performed, reducing operator manipulation and consequent radiological exposure. LIMS systems can be configured to maintain quality control charts and automatically validate results that comply with specifications.

A LIMS or similar computerized sample-tracking system will be required for high throughput analysis of the small volume samples. A full LIMS system should be able to direct the analysis flow, and collect and evaluate analytical data generated by the ICP/MS. Any sample-management plan will need to include disposal. Multi-tasking creates an analysis path that reduces bottlenecks in the analytical laboratory by, for example, sampling concurrent with dilution operations.

\subsubsection{Organic Sample Analysis}

Analysis of organic samples presents a particular challenge. Currently, back extraction using complexants is required to transfer constituents from the organic phase to an aqueous phase before many analyses (for example, ICP/MS or thermal-ionization mass spectrometry [TIMS]) can be done. This is time consuming, and as multiple back extractions are usually needed, a large volume of waste is generated relative to the initial sample.

With the high sensitivity of instruments such as the high-resolution inductively-coupled plasma mass spectrometer (HR-ICP/MS), one should be able to analyze very dilute organic samples that contain $30 \%$ tributyl phosphate (TBP) or other organophosphate compounds which cause problems with the ICP torch. To routinely perform direct organic dilution measurements, a critical need will the determination of an appropriate diluent that, upon injection, yields little carbonization on the torch. A review of the literature to identify potential candidate diluents and testing of those candidates should be pursued. If successful determined, the diluent would result in significant reduction in man-hour requirements and waste generation, compared with the back-extraction method. 


\subsection{Analytical Instrument Systems Recommended for Application Test/Development Program}

ICP/MS is a well developed, robust analytical technique that is well suited for safeguards, process control, and process optimization measurements. Many methods have been developed to determine both total elemental concentration (assay) and isotopic composition of the actinide elements in complex matrices, including spent fuel. Additionally, many of the longer-lived fission products are readily determined by ICP/MS. The complexity of spent-fuel and recycling-process solutions does require careful design and validation of analytical procedures to ensure all isobaric interferences are accounted for or removed. This often requires pre-treatment steps, including off-line or on-line radiochemical separations or the use of high-resolution instruments.

Several types of ICP/MS instruments are readily available and useful for determining actinides and fission products in process solutions. These include, in order of operating complexity, quadrupole instruments (ICP-QMS), HR-ICP/MSs, and multi-collector instruments (MC-ICP/MS). Each instrument has its advantages and limitations, although all have been successfully used for quantifying radionuclides. The simplest instruments use a quadrupole mass spectrometer (ICP-QMS) and are readily available from multiple manufacturers. These instruments are robust and relatively uncomplicated to run and maintain, making them ideal for process-control applications in which many sample analyses are required. Most commercial instruments are also available with collision cells (or dynamic-reaction cells), which eliminate or reduce polyatomic interferences frequently encountered when analyzing complex matrices like spent-fuel process solutions. An example of improved detection limits through the use of a dynamic reaction cell to eliminate polyatomic interferences is shown in Figure 2. ${ }^{1}$

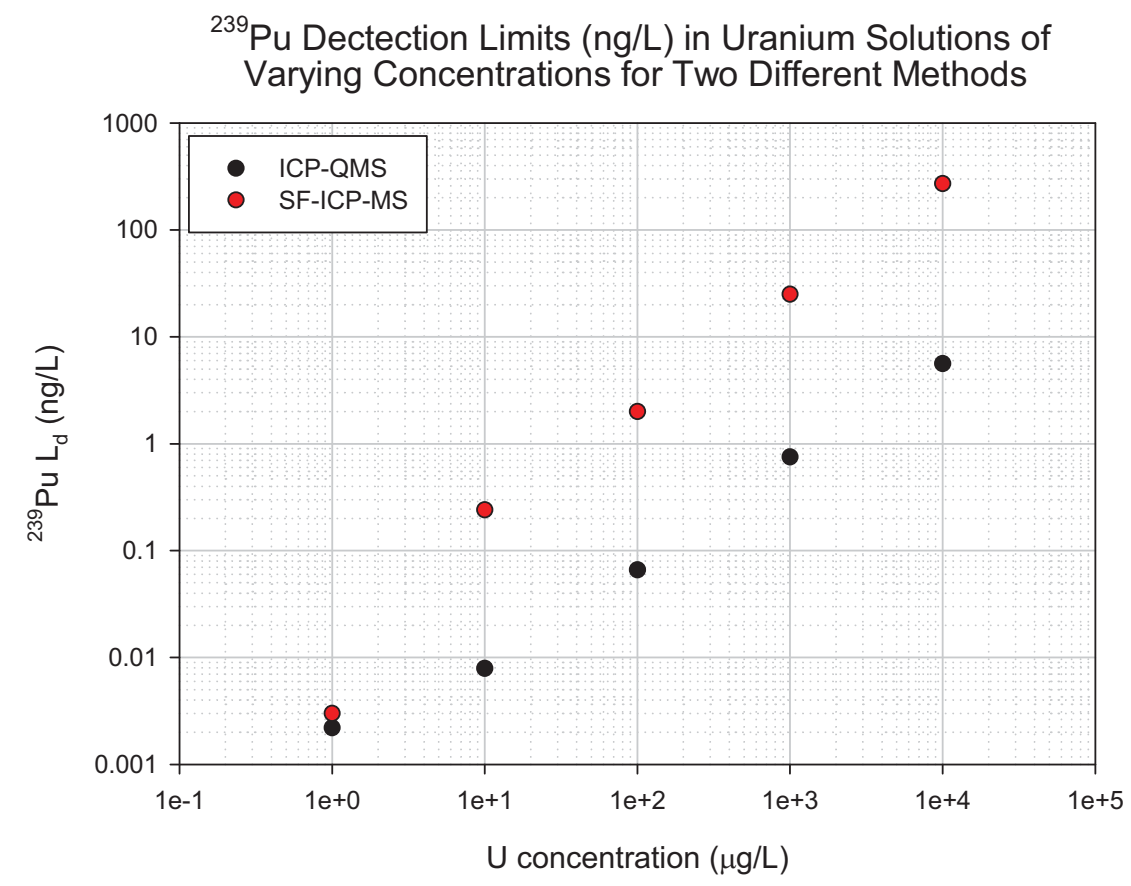

Figure 2. Detection limits for ${ }^{239} \mathrm{Pu}$ in uranium solutions. The use of a dynamic-reaction cell with an ICP-QMS actually produced better detection limits that using a SF-ICP/MS for the same analyses. ${ }^{1}$ 
Sector-field ICP/MS (SF-ICP/MS) instruments have sector-field mass spectrometers and, therefore, are capable of determining much smaller differences in mass than ICP-QMS instruments. Modern SF-ICP/MS instruments are capable of mass resolution of 10,000 or better and can have a linear dynamic range of up to 1012. However, since resolution is inversely proportional to sensitivity, it is not always advantageous to use SF-ICP/MS instruments at the highest possible resolution. Instead, the resolution may be tuned to the application, resulting in an adaptable analysis method, capable of determining analytes with a wide range of concentrations in complex matrices, like spent-fuel process solutions. Uranium, for example, is best run in the lowest resolution mode since there are minimal polyatomic interferences in most cases. Figure 3 shows the measurement precision for both the total uranium and the ${ }^{235} \mathrm{U} /{ }^{238} \mathrm{U}$ ratio measured using SF-ICP/MS in the three resolution modes. Another example demonstrates the usefulness of multiple resolution modes. Figure 4 shows the detection limit (Ld) for various isotopes in a solution containing $50 \mathrm{mg} / \mathrm{L}$ uranium. ${ }^{2}$ Note that different resolution modes are used to obtain the best detection limit for each isotope.
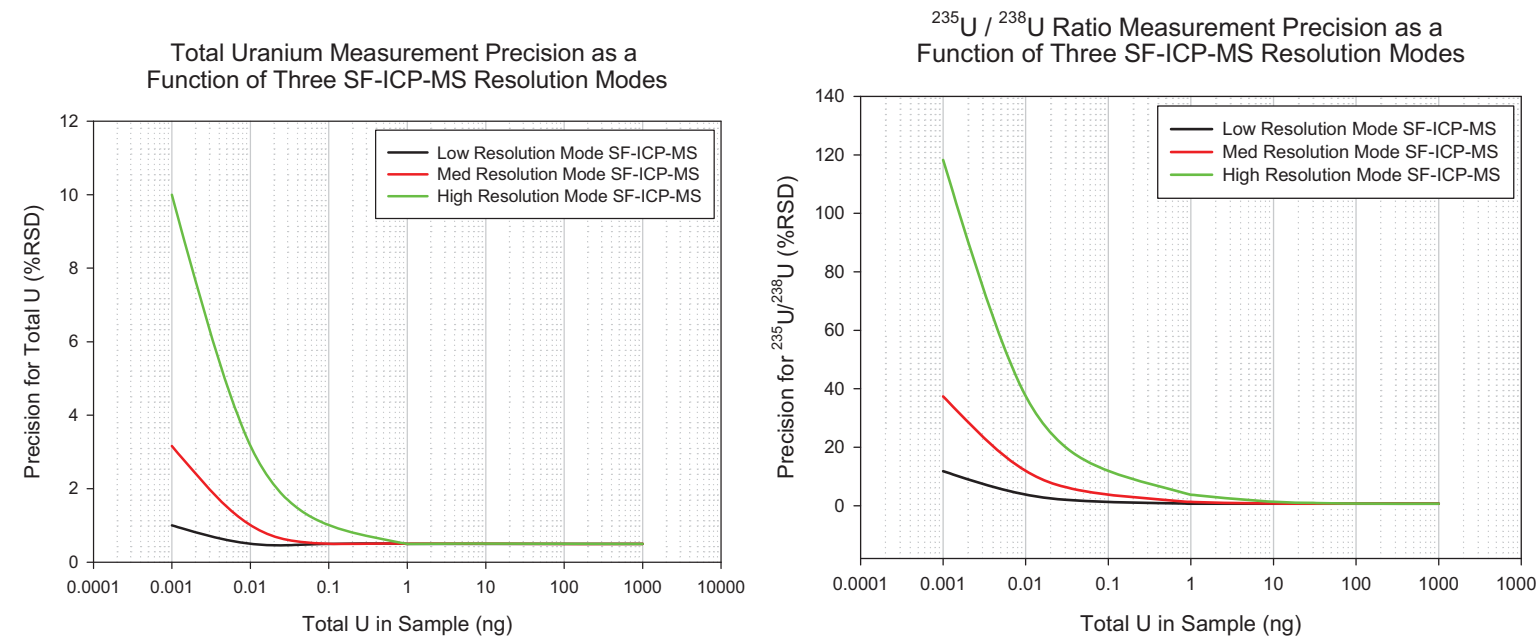

Figure 3. Measurement precision for Total $U$ (left plot) and ${ }^{235} U /{ }^{238} U$ (right plot) for a range of sample uranium contents. Note the log scale for the Total U axis. Given sufficient uranium, there is no benefit to using the lower resolution modes available with SF-ICP/MS. The precision converges to an approximate best value of $0.5 \%$ relative standard deviation $(k=1)$ for total uranium and $0.7 \%$ relative standard deviation $(k=1)$ for the ${ }^{235} \mathrm{U} /{ }^{238} \mathrm{U}$ ratio. 


\section{Estimated Detection Limits for Select Isotopes in the Presence of $50 \mathrm{mg} / \mathrm{L}$ Uranium}

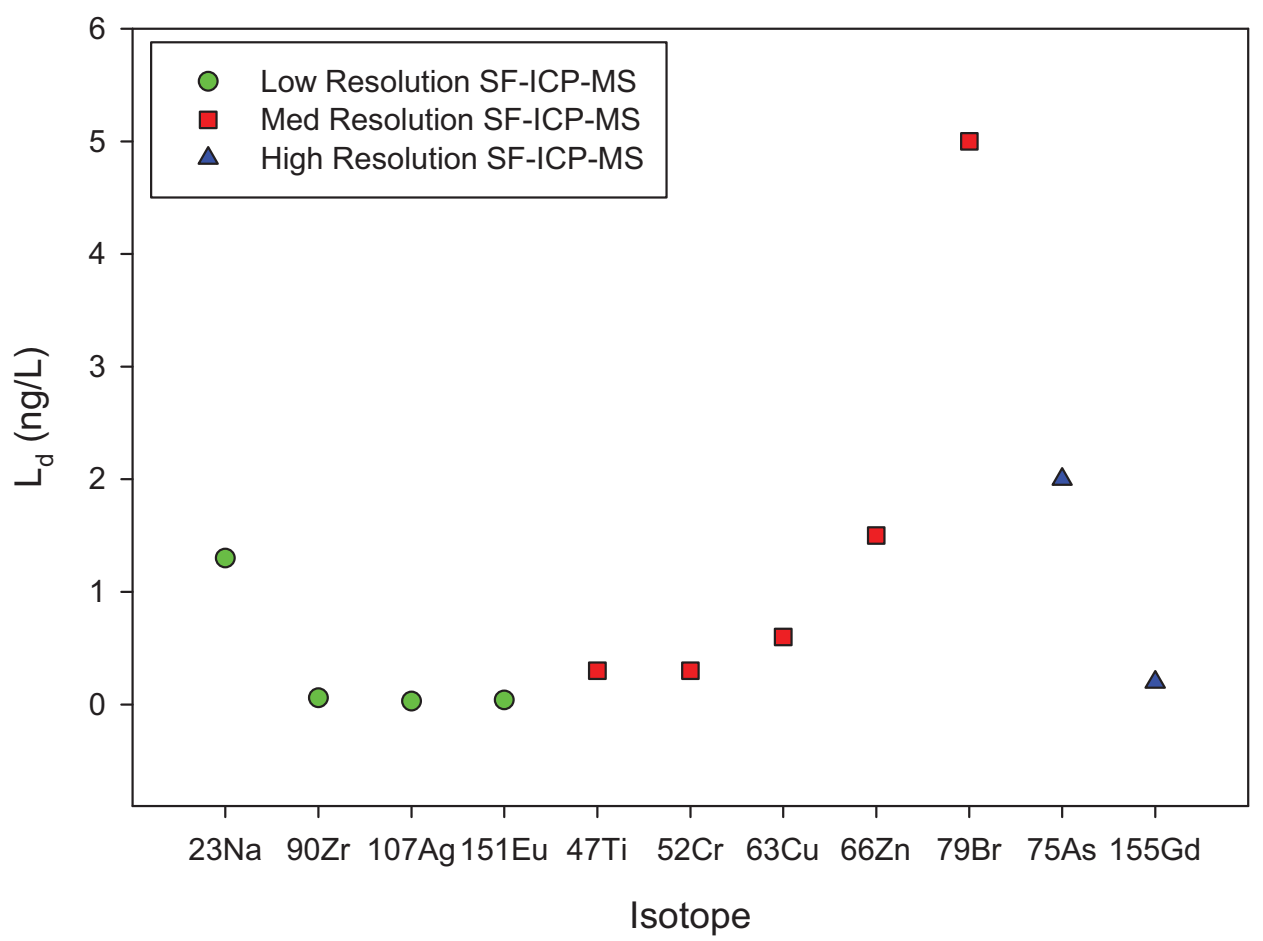

Figure 4. Estimated limits of detection for select isotopes in a $50 \mathrm{mg} / \mathrm{L}$ uranium solution. Note that the $\mathrm{SF}-\mathrm{ICP} / \mathrm{MS}$ allows resolution to be varied. At higher resolutions, it is easier to discriminate against interfering polyatomic ions while, at lower resolutions, overall sensitivity is usually better. ${ }^{2}$

Multi-collector ICP/MS (MC-ICP/MS) instruments also have sector-field mass spectrometers, but employ multiple detectors. Unlike ICP-QMS and SF-ICP/MS instruments, which have single detectors over which each isotope must be individually scanned, the MC-ICP/MS is able to simultaneously detect multiple isotopes. This provides for the ultimate in sensitivity, since there is no signal loss while scanning over a single detector. However, there are additional complications resulting from the multi-collector configuration, which arise from the need to carefully cross calibrate detectors for relative efficiency. Also, instruments are limited to a maximum of twelve detectors, which means only twelve isotopes may be determined per analysis. These instruments are also low-resolution, but they have both the highest abundance sensitivity and detection sensitivity of any ICP/MS methods. Due to the complexity of MC-ICP/MS instruments, they are likely not well suited to most spent-fuel process solution measurements. These instruments would provide the best uranium and plutonium isotopic composition measurements on radiochemically purified samples for safeguards.

Table 1. Typical capabilities for three common ICP/MS instruments.

\begin{tabular}{|l|l|l|l|}
\hline & \multicolumn{1}{|c|}{ ICP-QMS } & \multicolumn{1}{c|}{ SF-ICP/MS } & \multicolumn{1}{c|}{ MC-ICP/MS } \\
\hline Typical Detection Limits & Low ppm to high ppt & High ppb to low ppq & Low ppb to low ppq \\
\hline Resolution & $300-3000$ & $300-25,000$ & $500-2000$ \\
\hline Abundance Sensitivity & $10^{5}-10^{7}$ & $10^{6}-10^{7}$ & $10^{7}-10^{9}$ \\
\hline
\end{tabular}


The standard approach for introducing aqueous samples into an ICP/MS is through a nebulizer. There are many designs for nebulizers, which typically allow for sample flow rates from $0.1-3 \mathrm{~mL} / \mathrm{minute}$.

Nebulizers are tailored to the application; for example, concentric-flow nebulizers can be tailored to specific flow rates, and high-solids ( $\mathrm{V}$-groove) nebulizers resist the clogging to which most nebulizers are prone. Many methods for introducing samples to an ICP/MS have been investigated and can substantially improve measurement sensitivity and precision. While the ultimate in measurement sensitivity and precision are not necessary for the rigor characteristic of safeguards and process-control measurements, these advantages also mean smaller samples are needed to obtain the required measurement precision.

Ultra-sonic nebulizers can improve ionization efficiency by a factor of 10 over standard concentric-flow or spray-chamber nebulizers. For example, detection limits for plutonium using an ultra-sonic nebulizer on an ICP-QMS are as low as 10-30 ppq under ideal conditions. ${ }^{3}$ The use of high-efficiency nebulizers for determining actinides has also been demonstrated. ${ }^{4}$ These nebulizers, which typically have very low flow rates $(1-100 \mu \mathrm{L} / \mathrm{min})$, would be ideally suited to analysis of spent-fuel process solutions since they would allow for the collection of very small samples and produce an absolute minimum of waste. For comparison, a high-efficiency nebulizer will produce approximately 1700 counts/fg ${ }^{238} \mathrm{U}$, while an ultra-sonic will only produce about 600 counts/fg ${ }^{238} \mathrm{U}$, and a standard spray chamber, only 100 counts/fg ${ }^{238} \mathrm{U}^{4}$

\subsection{Sampling and ICP/MS Deployment Options}

There are three novel methods which might be employed for the analysis of metal ions in nuclear-fuel recycling-process aqueous streams. It may be feasible to employ specially designed auto-sampler equipment coupled with remotely employed ICP/MS instruments staged at various locations in the process. Second, the conventional sampling methods that employ shielded sample blisters and stainless-steel tubing and needles to re-circulate sample solutions from the process to the sample station may be miniaturized via the use of capillary tubing. The last approach to consider is the use of automated equipment to both directly sample and then transfer a microchip-based sample to AN ICP/MS located outside the radiation zone.

Remotely employed ICP/MS equipment is considered feasible, but would require many expensive instruments and special radiation shielding to protect electronics, and such an instrument would be difficult to maintain, calibrate, and service. Miniaturizing the conventional sampling methods via capillary tubing to reduce sample size, personnel exposure, and waste is troublesome to employ due to the tendency of capillary tubing to fail when solids form from residual solutions due to intermittent sampling. This technique might be useful for monitoring of a flowing stream that is continuously re-circulated to the process, but may not adapt well to an ICP/MS. If employable, this method may also require a large number of expensive instruments, one dedicated to each sample point. Thus the third option, the use of automated microchip techniques, appears the most promising and will be the focus of our discussions.

\subsection{Sample Systems Recommended for Application Test Development Program}

An entirely new method of acquiring and analyzing radioactive aqueous-solution samples during nuclear fuel reprocessing is required to further enhance the recycling of critical energy resources and the life-cycle management of remote-handled special nuclear material (SNM); that is, used nuclear fuel. A most promising route for acquiring representative samples appears to lie in the use of automated-to-transport capillary-based microchips. This system would acquire, transport, and introduce the sample directly to an ICP/MS.

Microchips containing miniscule capillary channels are being employed in a technology commonly called microfluidics. Microfluidics involves the handling and manipulation of minute amounts of fluids volumes thousands of times smaller than a droplet. The commercial application of microfluidics began 
almost twenty years ago with the advent of the ink-jet printer. Microfluidics embraces applications in chemistry, biology, medicine, and micro-electro-mechanical systems.

Microfluidics is a sea change for liquid handling in the laboratory environment. Most laboratory processes for high-throughput bioanalytical screening were based on titer-plate technology, parallel processing liquids in wells, each containing up to hundreds of microliters. As titer plates have miniaturized, evaporation of the liquids led to significant analytical accuracy problems. Precise transfer of small volumes of liquids to and from smaller wells also became increasingly difficult. Microfluidics, based on microcapillary chips, provide the basis for solution handling now being applied in biotechnology, drug discovery, chemistry and research in general. A "lab on a chip" is now being employed for electrophoresis-based separations, using microchip capillary methods for chemical analysis of samples such as complex as whole blood. For example, sodium, lithium, magnesium, and calcium can be separated in less than 20 seconds with a lithium detection limit of $0.15 \mathrm{mmol} / \mathrm{L} .^{5}$

This technology, applied to nuclear analytical chemistry, could simplify the accurate determination of important radioelements in the fuel-recycling processes. It could begin with the use of microcapillary samplers with automated means of drawing samples from clarified flowing streams and/or well-mixed tanks. These chips could contain multiple channels for elemental analyses and simultaneously provide duplicates to ensure precision. Automated transfer of these chips, with bar coding for tracking, could share an interface with spectrometers for both elemental and isotopic analysis. It is probable that instruments could be located inside Perma-Con stainless-steel structures to maintain contamination control while remaining available for direct maintenance, calibration, and control because source term for direct radiation levels and related contamination control would be on the order of at least 1000 times lower than today's sample.

Furthermore, the implementation of microfluidics using lab-on-a-chip technology could also provide gains in analytical simplicity, accuracy, and speed. Analytical solvent extraction at the microliter level is possible due to the unique formation of liquid layers when multiple liquids are brought into a single channel. ${ }^{6}$ Reactions and/or mass transfers occur in the vicinity of the interface due to laminar flow. Even miscible fluids form layers in this micro environment, allowing mass transfer in these systems as well.

Methods for remotely sampling representative, but very small amounts (microliters) of the process streams via microchip samplers and demonstrating the compatibility of the sample system with the analytical instruments will be required to take full advantage of this technology. Achieving this goal requires a remote-controlled and highly reliable sampling system that can

- Sample multiple points in the process

- Provide representative samples

- Collect only the volume needed for analysis

- Achieve these tasks in a matter of minutes rather than hours.

Microchannel fabrication processes have been demonstrated using timed wet-chemical etching methods to selectively etch sacrificial materials. ${ }^{7}$ The prototype glass and polysilicon microchannels thus produced have dimensions of $70 \times 4$ microns and $70 \times 2$ microns, respectively. Both microchannels have been tested to successfully transport and contain water by means of surface tension. A simplified surface tension analysis showed that the height of the etch holes and the surface tension of the working liquid inside the microchannel dominates the pressure difference that holds the liquid from leaking from the etch holes. Because these microchannels are fabricated using standard micromachining processes, the opportunity for economical prototyping and integration with other microfluidic devices is favorable. Further study of the feasibility of adapting and employing microfluidics to nuclear-related elemental and isotopic analysis is warranted. Implementing this advanced sampling system on an engineering scale is a key step to assuring successful operations in the next nuclear fuel cycle. 
Automation is becoming more prevalent in analytical, research, and many bioanalytical applications. Autosamplers are being employed for liquid chromatography with the ability to handle samples as small as 0.2 microliters. Fast cycle times of less than 15 seconds for 5 microliter samples are providing reliable, high-throughput analyses via such equipment as the Dionex Ultimate 3000 rapid-separation autosampler. Such equipment could be adapted for the introduction of very small samples into the ICP/MS or thermal atomization resonance ionization spectroscopy (TARIS) instruments.

The TARIS system potentially could be used to provide an advanced method of single-element isotopic analysis for the advanced nuclear fuel recycle facility. TARIS requires a very small sample volume (10 microliters), does not require sample dilution, and can differentiate between radionuclides with the same atomic weight (for example. between ${ }^{238} \mathrm{U}$ and ${ }^{238} \mathrm{Pu}$ ). These advantages would allow the TARIS system to be used to obtain near-real-time analysis of process streams, which will allow accurate tracking of accountable nuclear material throughout the process.

TARIS requires additional development/verification in order for the system to be implemented into an advanced fuel recycle facility. Further research includes investigation of the ability to analyze all isotopes of interest, automation of the system for multi element analysis, and methods for inputting the samples via microchip technology for direct analysis by the TARIS.

Implementation of these automated sampling and measurement technologies could provide significant improvements in the efficiency, speed, and accuracy of both Safeguards monitoring and process analysis. Reducing sampling time, sample sizes, analytical time, and direct personnel access will make it possible to collect more data, increase the frequency of sampling, limit personnel exposure, and further reduce risk of proliferation. Additional improvements could include:

- Increased accuracy and decreased measurement uncertainty

- Reduced/optimized process holdup tank sizes for analytical sampling and analysis

- Reduced facility footprint for analytical services

- Reduced facility footprint for holdup tanks for analytical sampling and analysis

- Reduced facility footprint for waste treatment services related to analytical waste

- Optimized operations and decreased down time for analytical results

- Increased frequency of process sampling, significantly lowering the sample volume and reducing analytical measurement time

- Extended time between process inventory balances via improved accuracy/sample frequency

- Reduced time for analytical measurements, allowing more frequent sampling, thus minimizing the amount of material that can be diverted without detection

- Enhanced process control

- Minimized radioactive waste and sample volume recycle

- Reduced or simplified wet-chemical analyses via fewer samples, smaller volumes, less complex sample preparation, and fewer steps

- Secure and reliable data analysis, transmission, output, and tracking. 


\subsection{Micro Nebulizer Coupled to a Micro ICP Generator - The Future}

Appendix A defines the ICP/MS by examining the input and output streams for each section of the instrument. Typically, it consists of a sampling system, a sample-introduction section, a plasma generator, an interface to the vacuum system, an ion-focusing lens, a mass analyzer, and an ion detector. The majority of the sample and the carrier gas is lost as waste in the sample-introduction section and the plasma generator. Approximately $95 \%$ of the sample introduced to the nebulizer is returned as waste at the output of the spray chamber due to improper droplet size. Only $5 \%$ of the sample and $100 \%$ of the carrier gas is introduced to the ICP generator. The ICP generator ionizes the carrier gas which in turn disassociates the sample molecules into singly ionized atoms. Another $12-17 \mathrm{~L} / \mathrm{min}$ of carrier gas is added at this section and is returned in the waste stream at the output of the ICP generator. Only $1 \mathrm{~L} / \mathrm{min}$ of the carrier-gas plasma containing the sample is then introduced into the mass analyzer, where only a small amount of the sample is delivered to the detector.

Another way to look at it is by comparing the number of atoms introduced as sample compared to the number of ions counted by the detector. Assume that a $0.1 \mathrm{~mL}$ sample introduced at $0.1 \mathrm{~mL} / \mathrm{min}$ contains $4.5 \times 10^{11}$ atoms. This corresponds to $7.4 \times 10^{9}$ atoms per second introduced into the system. Appendix A calculates that only $1.9 \times 10^{5}$ ions per second reach the detector. The majority are lost in the plasma-vacuum interface and the ion-focusing section. A significant portion of the sample (95\%) and $94 \%$ of the carrier gas is lost in the nebulizer and ICP-generator output. This means that a reduction in the nebulizer and ICP-generator waste streams would directly result in a reduction of the sample size.

Microchip nebulizers designed for mass spectrometry have been reported to operate with sample streams as low as $0.0001-0.01 \mathrm{ml}$ and $100 \mathrm{sccm} \mathrm{N}_{2}$ carrier gas. ${ }^{8}$ Conservatively, this could result in a factor of at least one order of magnitude reduction of the sample and carrier gas. Research into the development of microplasma generators that can operate in air by Hopwood, et alia, ${ }^{9}$ is also promising. They report good performance without plasma-induced erosion after 50 hours of operation. Thus, the coupling of such devices to an ICP/MS may be feasible for elemental analysis under automated control and may support use of such small samples for our analytical purposes. The capability to analyze samples 1000-times smaller than those currently used would have a dramatic impact on sample-acquisition, time, sample-system design, and reductions in waste generation and radiation exposure. 


\section{APPLICATION TEST PROGRAM PLAN}

The following high-level requirements outline the research and development efforts needed to evaluate the feasibility of utilizing an automated, microchip-based sampling and analysis system for use in nuclear-fuel recycling process and Safeguards purposes:

- Establish preliminary microchip requirements, volume per capillary, number of capillaries, chip dimensions, and sample analytical figures of merit (INL, Argonne National Laboratory [ANL], and Los Alamos National Laboratory [LANL])

- Source-sample microchips for testing, establish feasibility, study sample attributes (INL)

- Define automation requirements for taking microchip samples (INL, ANL, LANL)

- Identify physical sample points and requirements (INL)

- Create preliminary design of equipment for sampling at point of sample (INL)

- Identify candidate methods of moving loaded microchip to ICP/MS (ANL, LANL)

- Make preliminary evaluation of minimum size sample for ICP/MS analysis ANL, LANL

- Identify ICP/MS feasibility and modifications needed for micro-liter sample ANL, LANL

- Identify test plan high-level requirements on a sample system by sample system basis

- Identify the test plan resources (facility/personnel) required

- Identify the best candidate lab (INL, LANL, ANL or university) to perform each test

- Identify order of magnitude test-program costs

- Identify reporting requirements

- Identify an expected schedule.

Addressing the above requirements in a formal report will constitute the first milestone of FY-10. The remaining work for next year will concentrate on implementing the research activities defined in that report. 


\section{CONCLUSIONS}

This report has scoped the major challenges for defining and testing improvements to current aqueous sampling and analytical techniques and has identified key potential benefits that can be gained when these concepts are implemented in future reprocessing facility designs. The primary goal to create transcendental improvements in all areas: reduced proliferation risks, improved operational control and efficiency, reduced analytical waste, reduced facility footprint (analytical and process areas) and capital costs, decreased personnel exposure, etc remains a work in progress.

These preliminary findings represent an initial effort to (1) define a comprehensive view of the work scope for aqueous sampling and (2) focus on one of many critical path issues that need additional study. As indicated in Section 5.0 much remains to be done on ICP/MS feasibility and modifications needed for analyzing micro-liter size samples. Limited scope for this effort led to a quick-down selection of a critical path issue and other assumptions about "big picture" issues to bound the project and provide value-added results. However, other specific, detailed studies related to big-picture and other issues still need investigation.

As previously mentioned, this is a work in progress that is intended to be conducted in phases, and future work should consider addressing these trade-off big-picture issues because they can have a significant impact on the design and operational requirements of an analytical system; for example, is it better to operate a reprocessing facility in a phased or continuous manner? Can the analytical support system be co-located within the process facility or is it so large it has to be a stand-alone facility? Answers to these issues will, of course, also impact the scope of the analytical support systems. Developing an integrated set of investigations that complement and build on targeted findings will continue to be a key programmatic driver for understanding the challenges related to optimization of the sampling and analytical support for a nuclear-fuel reprocessing facility. 


\section{REFERENCES}

1. Tanner, S. D., Li, C., Vais, V., Baranov, V., and Bandura, D., Chemical Resolution of Pu+ from U+ Using a Band-Pass Reaction Cell Inductively Coupled Plasma Mass Spectrometer, Anal. Chem., 76, 3042-3048, 2004.

2. Thermo Scientific Element 2 \& Element XR Product Guide, 2008.

3. Gries, C., Karlsson, S., Duker, A., Pettersson, H., and Allard, B., Determination of plutonium in environmental samples with quadrupole ICP/MS, J. Radioanal. Nucl. Chem., 275 (1), 55-70, 2008.

4. McLean, J. A., Becker, J. S., Boulyga, S. F., Dietze, H., and Montaser, A., Ultratrace and isotopic analysis of long-lived radionuclides by double-focusing sector field inductively coupled plasma mass spectrometry using direct liquid sample introduction, Int. J. Mass Spectrometry, 208, 193-204, 2001.

5. Vrouwe, E. X., Luttge, R., Vermes, I., and van den Berg, A., Microchip Capillary Electrophoresis for Point-of-Care Analysis of Lithium, Clinical Chemistry, 53 (1), 117-123, 2007.

6. Hotta, T., Nii, S., Yajima, T., and Kawaizumi, F., Mass Transfer Characteristics of a Microchannel Device of Split Flow Type, Chem. Eng. Technol., 30, (2), 208-213, 2007.

7. Lee, K.B., and Liwei, L. Surface Micromachined Glass and Polysilicon Microchannels using MUMPs for BioMEMS Applications, Sensors and Actuators A: Physical, 111(1), 44-50, 2004.

8. Saarela V. HaapalaM, Kostiainen R, Kotiaho T, and Franssila S 2007 Glass Microfabricated Nebulizer Chip for Mass Spectrometry, Lab Chip: 7 644-6.

9. Hopwood, J., Iza, F., Coy, s., and Fenner, d.b., A Microfabricated Atmospheric Pressure Microplasma Source Operating in Air, J. Phys. D: Appl. Phys., 38, 1689-1703, 2005. 
Enhanced AFCI Sampling, Analysis, and Safeguards Technology Review 


\section{Appendix A}

\section{Inductively-Coupled-Plasma Mass Spectrometer: A Definition, Including Input and Output Streams}


Enhanced AFCI Sampling, Analysis, and Safeguards Technology Review 


\section{Appendix A}

Inductively-Coupled-Plasma Mass Spectrometer: A Definition, Including Input and Output Streams

\section{A-1. INTRODUCTION}

The instrument of choice for this Enhanced AFCI Sampling, Analysis, and Safeguards Technology Review is the inductively-coupled plasma mass spectrometer (ICP/MS). It was chosen for its wide elemental coverage, high sensitivity, fast analysis, small sample size, and wide dynamic range. The following is a description of the ICP/MS, with its input and output streams, to define a baseline for researching sample delivery and preparation systems. Most of the information is derived from the Agilent Technologies publication, "ICP/MS Inductively Coupled Plasma Mass Spectrometry, A Primer."

A mass spectrometer is an analytical instrument that generates from a sample a set of numbers that represent units of mass divided by charge $(\mathrm{m} / \mathrm{z})$. This set represents the $(\mathrm{m} / \mathrm{z})$ ratio for each ion of an input processed sample delivered to the detection stage of the spectrometer. Each ion's mass is recorded in a histogram format; $(\mathrm{z})$ represents the charge of a singly ionized ion (that is, the charge of an electron, or the constant $1.6 \times 10^{-19}$ coulomb). The $\mathrm{m} / \mathrm{z}$ ratio can be determined from the mass $(\mathrm{m})$ of the ion through multiplication by charge. The mass spectrometer accepts the introduction of (in this case) a liquid sample and, after a short period of time, calculates, records, and displays a set of mass numbers. In parallel, a waste stream is delivered to a waste-handling system.

The process y which these numbers are developed is far more complicated. The following describes this process for the ICP/MS quadrupole, magnetic sector, and time-of-flight mass-measurement systems. Also addressed is the ion-specific laser-induced ionization front end, feeding a time-of-flight mass spectrometer called TARIS.

\section{A-2. SYSTEM DESIGN}

Absent consideration of the data acquisition component, most mass spectrometers have a sampling system, a sample introduction section, a plasma generator, an interface to the vacuum system, an ion focusing lens, a mass analyzer, and an ion detector.

\section{A-2.1 Sampling System}

A sampling system can be defined as any device or combination of devices that draws a sample containing the analyte from either a sample vial or a process to the sample introduction section of the mass spectrometer. It may consist of a low-volume metering pump drawing from a single cuvette or a tray of cuvettes that is mounted on an automated sequencing system such that human involvement is minimal. A more complex sampling system would consist of a combination of valves, tubing, filtration, dilution, and separation equipment that ultimately delivers a sample containing the processed analyte to the sample introduction section. The majority of development work will probably be devoted to this area.

\section{A-2.2 Sample Introduction}

The liquid-sample introduction system converts the sample into an aerosol and transports the properly sized droplets to the plasma introduction section of the mass spectrometer. The sample introduction system generally consists of a nebulizer and a spray chamber. The nebulizer has two input streams, one for the carrier gas (generally argon) and the other delivering the liquid sample. The carrier-gas stream can range in flow from $0.8-1.4 \mathrm{~L} / \mathrm{min}$. The liquid-sample stream can deliver from $2.5-0.02 \mathrm{~mL} / \mathrm{min}$. The output stream contains liquid sample converted to droplets and mixed with the carrier gas. The output stream is then introduced to a spray chamber, from which smaller droplets and gas are ultimately 
introduced to the plasma generator. Larger droplets are removed from the aerosol as a liquid and a gas, and these constitute a waste stream. The ratio between liquid sample delivered to the plasma generator and liquid sample delivered to the waste stream is about $5 \%$; thus, most of the sample stream is not delivered to the inductively-coupled plasma (ICP) generator. The ratio between carrier gas delivered to the plasma generator and that delivered to the waste stream is $100 \%$. Assume a $0.1 \mathrm{~mL} / \mathrm{min}$ sample introduction rate of $1 \mathrm{ppb} C \mathrm{Cs}$. This sample would contain approximately $4.5 \times 10^{11}$ atoms. The $\mathrm{Cs}$ atom flow rate at $0.1 \mathrm{~mL} / \mathrm{min}$ is $7.5 \times 10^{9}$ atoms per second.

\begin{tabular}{|l|l|l|}
\hline \multicolumn{1}{|c|}{ Input Streams } & \multicolumn{1}{|c|}{ Output Streams } & \multicolumn{1}{c|}{ Waste Streams } \\
\hline $0.1 \mathrm{~mL} / \mathrm{min}$ sample & $0.005 \mathrm{~mL} / \mathrm{min}$ sample droplets & $0.085 \mathrm{~mL} / \mathrm{min}$ sample \\
$1 \mathrm{~L} / \mathrm{min}$ carrier gas & $0.01 \mathrm{~mL} / \mathrm{min}$ water vapor & \\
& $1 \mathrm{~L} / \mathrm{min}$ carrier gas & $0 \mathrm{~L} / \mathrm{min}$ carrier gas \\
\hline
\end{tabular}

\section{A-2.3 Plasma Generation}

The ICP plasma generator uses a radio frequency (RF) oscillator and amplifier to generate an RF magnetic field using a small coil surrounding the plasma generation volume. The magnetic field accelerates charged particles (ionized carrier gas) to high velocities which, in turn, lose energy in the form of heat upon impact with other carrier-gas molecules. Temperatures on the order of 6,000-10,000 K are generated. This energy is then used to dissociate the molecules in the aerosol into singly ionized atoms for delivery into the mass spectrometer. The ICP requires three gas (generally argon) input streams and produces one output stream. A plasma-gas input stream is heated by the RF magnetic field, requiring about $12-17 \mathrm{l} / \mathrm{min}$. This plasma is used to heat the carrier/nebulizer gas containing the analyte. The carrier/nebulizer gas runs at about $1 \mathrm{l} / \mathrm{min}$. A third input stream consists of coolant gas to protect the plasma generator; it also requires about $1 \mathrm{l} / \mathrm{min}$. The output stream is singly-ionized carrier gas and analyte. This is delivered to the plasma-vacuum interface. The output is the sum of the three input streams at about $6,000-10,000 \mathrm{~K}$.

\begin{tabular}{|l|l|l|}
\hline \multicolumn{1}{|c|}{ Input Stream } & \multicolumn{1}{|c|}{ Output Stream } & \multicolumn{1}{c|}{ Waste Stream } \\
\hline $\begin{array}{l}0.005 \mathrm{~mL} / \mathrm{min} \text { sample droplets } \\
0.01 \mathrm{~mL} / \mathrm{min} \text { water vapor } \\
15+2 \mathrm{~L} / \mathrm{min} \text { carrier gas }\end{array}$ & $\begin{array}{l}0.005 \mathrm{~mL} / \mathrm{min} \text { ionized sample } \\
17 \mathrm{~L} / \mathrm{min} \text { carrier gas }\end{array}$ & $\begin{array}{l}\text { See the plasma vacuum } \\
\text { interface waste stream. }\end{array}$ \\
\hline
\end{tabular}

\section{A-2.4 Plasma-Vacuum Interface}

The role of the plasma- vacuum interface is to extract a representative sample of the plasma and deliver it to the high-vacuum chamber, where the ion focusing, mass analyzer, and ion detector are located. It consists of two cones with a small orifice drilled at the apex of each cone. The output of the plasma generator is directed at the orifice of the first cone (sampler). The ions enter a low-vacuum chamber, were they are directed toward the orifice of the second cone (called the skimmer). After passing through the second cone, ions, traveling at a high velocity, are introduced into the high-vacuum chamber. The plasma-vacuum interface has one input stream and several output streams. The input stream is the output of the plasma generator directed through the first cone. The first output stream is a waste stream, consisting of the majority of the input stream, less the small portion that passes through the first cone's orifice. The second output stream is the solids residue that collects on the surface of the cone so that the cone should be cleaned periodically to remove this waste. The volume of this waste stream depends on the sample, but is not considered to be negligible. The output of the first cone is directed toward the input of the second cone. 


\begin{tabular}{|l|l|l|}
\hline \multicolumn{1}{|c|}{ Sampler Input Stream } & \multicolumn{1}{|c|}{ Sampler Output Stream } & \multicolumn{1}{|c|}{ Sampler Waste Stream } \\
\hline $0.005 \mathrm{~mL} / \mathrm{min}$ ionized sample & $0.0025-0.005 \mathrm{~mL} / \mathrm{min}$ ionized & $0.0-0.0025 \mathrm{~mL} / \mathrm{min}$ ionized \\
$17 \mathrm{~L} / \mathrm{min}$ carrier gas & sample & sample \\
& $1 \mathrm{~L} / \mathrm{min}$ carrier gas & $16 \mathrm{~L} / \mathrm{min}$ carrier gas \\
\hline
\end{tabular}

Because of the relative small size of inputs, the units of measure for the streams now shift from $\mathrm{mL} / \mathrm{min}$ single atoms $/ \mathrm{sec}$. One L $/ \mathrm{min} \mathrm{Ar}$ (at room temperature) corresponds to $4.5 \times 10^{20}$ atoms $/ \mathrm{sec}$ Ar flow. The Ar gas flow through the sampler is estimated to be about $5 \times 10^{20}$ atoms $/ \mathrm{sec}$, depending on gas temperature. It is most comparable to the Ar-gas flow of the injector gas. Assuming $100 \%$ sample introduction into the sampler cone, a $0.005 \mathrm{~mL} / \mathrm{min}$ sample flow with $1 \mathrm{ppb} \mathrm{Cs}$ is the equivalent of a $3.8 \times 10^{8}$ ions/sec Cs flow.

\begin{tabular}{|l|l|l|}
\hline \multicolumn{1}{|c|}{ Skimmer Input Stream } & \multicolumn{1}{c|}{ Skimmer Output Stream } & \multicolumn{1}{c|}{ Skimmer Waste Stream } \\
\hline $\begin{array}{l}3.8 \times 10^{8} \text { ions } / \text { sec sample } \\
5 \times 10^{20} \text { atoms/sec carrier gas }\end{array}$ & $1.9 \times 10^{6}$ ions $/ \mathrm{sec}$ sample & $3.76 \times 10^{8}$ ions $/ \mathrm{sec}$ \\
& $1 \times 10^{18}$ atoms $/$ sec carrier gas & $4.99 \times 10^{20}$ atoms $/$ sec carrier gas \\
\hline
\end{tabular}

\section{A-2.5 Vacuum System}

A vacuum system is required to reduce the pressure in the ICP/MS from atmospheric pressure, at the location where the plasma is generated, to a ultra high vacuum in the chamber where the mass separation and detection take place. Usually a roughing pump and a high-vacuum pump, such as a diffusion or turbo molecular pump, are required. The input stream consists of air molecules, carrier-gas molecules, and leftover analyte molecules that have entered the plasma-vacuum interface, but have not plated out or passed into the ion-focusing section. The waste stream consists of these components.

\begin{tabular}{|l|l|l|}
\hline \multicolumn{1}{|c|}{ Input Stream } & \multicolumn{1}{c|}{ Output Stream } & \multicolumn{1}{c|}{ Waste Stream } \\
\hline $\begin{array}{l}3.76 \times 10^{8} \mathrm{ions} / \mathrm{sec} \\
4.99 \times 10^{\wedge} 20 \text { atoms } / \mathrm{sec} \text { carrier gas }\end{array}$ & Not applicable & $\begin{array}{l}3.76 \times 10^{8} \text { ions } / \mathrm{sec} \\
4.99 \times 10^{\wedge} 20 \mathrm{atoms} / \mathrm{sec} \text { carrier } \\
\text { gas }\end{array}$ \\
\hline
\end{tabular}

\section{A-2.6 lon Focusing}

The ion-focusing section focuses the plasma leaving the plasma-vacuum interface into a narrow beam and prepares it for introduction into the quadrupole mass separator by removing any leftover photons and neutral atoms. The input stream consists of ionized analyte, photons, and neutral atoms. Two output streams are produced. The first consists of the ionized analyte that is passed on to the quadrupole, and the second consists of the neutral atoms that are deposited in the ion-focusing section.

\begin{tabular}{|l|l|l|}
\hline \multicolumn{1}{|c|}{ Input Stream } & \multicolumn{1}{c|}{ Output Stream } & \multicolumn{1}{c|}{ Waste Stream } \\
\hline $\begin{array}{l}1.9 \times 106 \text { ions } / \text { sec sample } \\
1 \times 10^{18} \text { atoms } / \text { sec carrier gas }\end{array}$ & $\begin{array}{l}1.9 \times 10^{5} \text { ions } / \text { sec sample } \\
1 \times 10^{16} \text { atoms } / \text { sec carrier gas }\end{array}$ & $\begin{array}{l}1.7 \times 10^{6} \text { ions } / \text { sec sample } \\
\text { deposited neutral atoms. }\end{array}$ \\
\hline
\end{tabular}




\section{A-2.7 Mass Analyzer}

The mass analyzer section is required to create an ion stream consisting of the desired ions less all other (undesired) ions. This stream is the sent to the detector for counting. The mass analyzer of choice is the quadrupole. It performs this function by applying a direct-current voltage biased high-frequency potential between the four quadrupole electrodes. Separation is accomplished by introducing the ion stream into the input of the quadrupole at high velocity. The charged atoms are accelerated perpendicular to their velocity vector by the alternating electric field applied to the electrodes. Only ions of a specific mass-to-charge $(\mathrm{m}: \mathrm{z})$ ratio are passed on to the detector. All others become unstable and deviate from their velocity vector and, thus, do not impact the detector. All ions are singly charged, so the force acting on each ion is the same, making the quadrupole an ion mass separator. By varying the bias and high frequency potential, the quadrapole can be tuned to a specific m:z ratio. The quadrupole can be swept through a large range of $\mathrm{m}: \mathrm{z}$ ratios very quickly. The input stream is the introduced high-velocity ion stream that is the output of the ion-focusing section. Two output streams exist. The first is the ion stream that impacts the detector and amounts to approaching $100 \%$ of the tuned-for ions entering the quadrupole. The second is the input stream less the detected ions. It consists of the carrier gas and the other analytes in the sample. The second stream is carried off by the vacuum system or is deposited in the mass analyzer section.

\begin{tabular}{|c|c|c|}
\hline \multicolumn{1}{|c|}{ Input Stream } & Output Stream & Waste Stream \\
\hline $\begin{array}{l}1.9 \times 10^{5} \text { ions } / \text { sec sample } \\
1 \times 10^{16} \text { atoms } / \text { sec carrier gas }\end{array}$ & $1.9 \times 10^{5}$ ions $/$ sec sample & $1 \times 10^{16}$ atoms $/$ sec carrier gas \\
\hline
\end{tabular}

\section{A-2.8 Ion Detection}

The ion detector counts individual ions. This is accomplished when ions impact a material that produces a number of electrons for each impact. Each electron is then accelerated by a high potential and, upon impacting the same material, generates several more electrons, which are, in turn accelerated. Thus, the detector acts an electron multiplier. Eventually, sufficient electrons are produced that their total can be measured and counted as a single pulse for each ion. The input stream is the ion stream of interest that leaves the quadrupole and is directed toward the detector input. The output stream is made up of ions that are deposited in the detector. An output stream does not exist. The detector requires periodic replacement.

\begin{tabular}{|c|l|l|}
\hline Input Stream & \multicolumn{1}{|c|}{ Output Stream } & \multicolumn{1}{c|}{ Waste Stream } \\
\hline $1.9 \times 10^{5}$ ions $/$ sec sample & Not applicable & $\begin{array}{l}\text { Those ions that are deposited on } \\
\text { the detector surface }\end{array}$ \\
\hline
\end{tabular}

\section{A-3. VARIANTS}

The ICP/MS has undergone several modifications to enhance the original capability and produce variations of the basic design. Some of those are discussed below.

\section{A-3.1 Ultrasonic Nebulizer}

A variation of the gas nebulizer is the ultrasonic nebulizer. It uses mechanical vibrations in the $200 \mathrm{kHz}-10 \mathrm{MHz}$ range, instead of gas, to reduce fluid to fine droplets. Detection-limit reduction by a factor of 10 is claimed. The ratio between droplets delivered to the ICP and to waste stream liquid rises to about 10 to $15 \%$. The ultrasonic nebulizer also requires about $1.0 \mathrm{~L} / \mathrm{min}$ of carrier gas. 


\section{A-3.2 Laser Ablation}

Laser ablation replaces the traditional liquid nebulizer with a system that uses a laser to ablate the surface of a solid and turn it into an aerosol of small-diameter particles. It is intended for direct analysis of solids and powders without sample digestion. Spot sizes ranging from 750-5 $\mu \mathrm{m}$ are typical. A spot size of $5 \mu \mathrm{m}$ results in an incredibly small sample volume. A carrier gas then conveys the aerosol into the ICP section of a traditional ICP/MS.

\section{A-3.3 Magnetic Sector}

Some ICP/MS systems replace the quadrupole mass filter with a magnetic sector component. This allows for resolving masses less that $1 \mathrm{AMU}$, which may allow for isotope detection. Ions are accelerated to a high velocity and passed perpendicularly through a magnetic field. The relationship between the velocity vector and the magnetic-field vector causes a force to act on the ion that results in its deviating from its original path. The deviation is measured and related to the mass through a set of detectors.

\section{A-3.4 TARIS}

TARIS is a time-of-flight mass spectrometer based on a thermally ionized sample coupled with selective laser elemental-group ionization. A small sample is thermally atomized on a hot cell. The atoms to be analyzed are selectively and efficiently ionized by lasers. One laser is used to excite the atom, and the other ionizes it. The selected ions are then delivered to the input of a time-of-flight mass spectrometer, where they are accelerated and then delivered to a field-free flight tube. The mass is measured based on the time it takes the ions to reach the detector. Sample sizes can be as small as $10 \mu \mathrm{L}$. TARIS appears to be a good choice when considering minimal secondary waste generation. The waste stream appears to be mainly cooling water.

\section{A-4. SUMMARY}

The ICP/MS is capable of measuring the concentrations of several elements simultaneously in sub $\mathrm{mL}$ liquid samples. It is sensitive, and analysis time is fast. It requires the sample and a carrier gas, which is typically Ar. While the sample volume is small $(<1.0 \mathrm{~mL} / \mathrm{min})$, the carrier gas volume can be quite large $(\sim 17 \mathrm{~L} / \mathrm{min})$. A minute amount of the sample $(0.0025 \%)$ and carrier gas is actually used in the mass separation and detection sections. From a sample extraction, transportation, analysis, and waste stream point of view, significant advances could be made by ICP/MS modifications that allowed for ion detection by introducing only the amount of sample into the instrument that is required for detection. On the surface, the two obvious areas for advancement without changing the mass analysis and detection technology are in nebulizer design and plasma generation. A $100 \%$ efficient nebulizer would allow the sample volume to be reduced by a factor of 20 , and a plasma generator that did not require $16 \mathrm{~L} / \mathrm{min}$ of carrier gas would reduce that waste stream to near zero. Sample dilution would be a solution when considering the above example from the human exposure point of view. 